\title{
Book Reviews: Can China Lead the New World?
}

\author{
Alf Walle \\ University of Alaska at Fairbanks
}

Can China Rule the New World is a timely book that raises profoundly essential issues regarding China's growing economic power and its evolving spheres of influence. The mission of the book is to present views that are held by contemporary Chinese leaders, strategists, and intellectuals. Westerners have long complained about the "guile of the Orient." This book provides an analysis that can help the Western reader to understand better the Chinese people, who Westerners have often considered to be mysterious and unpredictable. It also provides a useful commentary regarding contemporary Chinese thinking and strategies along with a discussion of their implications to politics and economics.

A timely book with a provocative title Can China Rule the New World, authored by Tian Guang and Chen Gang, published by North American Business Press recently. It raises profoundly essential issues regarding China's growing economic power and its evolving spheres of influence. By doing so, the commentary encourages useful self-reflection within the Western world as well as providing Westerners with a more informed view of China.

The text is divided into three discrete but interconnected sections. Part 1 deals with what the authors refer to as some "conjectures" or speculations regarding possible futures in which China potentially emerges as the world's dominant social and economic force. The second section looks backward towards historical eras when China was a dominant force in the world, suggesting that the country and its people continue to have that potential. The analysis concludes with discussions regarding the implications of China's conceivable future dominance or, in contrast, China's possible acceptance of a more subordinate role.

The mission of the book is to present views that are held by contemporary Chinese leaders, strategists, and intellectuals. This is the authors' goal, not giving their own opinions. As a result, the text provides insights regarding Chinese thought in ways that can help Westerners understand and comprehend contemporary China and appreciate the challenges of dealing with China in effective and equitable ways.

In these accounts, Tian and Gang do more than provide evenhanded reports because they document that many Chinese thinkers possess strong and emotionally-laden views. Extrapolations of opinions and paradigms held by economic and cultural rivals are much needed. Westerners have long complained about the "guile of the Orient." Tian and Gang provide an analysis that can help the Western reader to understand better the Chinese people, who Westerners have often considered to be mysterious and unpredictable.

Although many readers might find parts of the book to be controversial, the authors are uniquely poised to present an analysis of how the Chinese nation and its people view the current situations, risks, and opportunities they face, as well as the implications of potential growth, power, and dominance. Both authors are business anthropologists who, raised in China, have long-term experience in the United States, serving as professors of business. Having one foot in China and the other in the West, they possess the breadth of 
perspectives necessary to tackle the complex issues they address. Tian and Gang do so by mixing and juxtaposing historical discussions with an analysis of current events.

The need to focus on these issues has grown substantially in recent years. China is currently challenging the status quo by, for example, asserting unprecedented rights to the South China Sea and demanding reunification with Taiwan. Its One Belt, One Road initiative is a massive investment in infrastructures that are designed to connect China with the developing world in ways that are intended to provide the country with permanent economic advantages. And China's growing investments in the military reminds me of Otto von Bismarck's observation that wielding military power is politics by another means. More than ever before, Westerners need to understand how the Chinese think about their country and the outside world. Tian and Gang's book is useful in that regard.

As a matter of personal taste, I am most drawn to section 2 that provides a detailed historical context presented from a Chinese perspective. It starts with a discussion of China's legacy as an unrivaled civilization, moves on to discuss both the strengths and weaknesses of Chinese culture, and concludes with a discussion of the pros vs. the cons of economic development. Doing so provides the reader with an analysis of how Chinese thinkers perceive the fact that after being a dominant civilization for thousands of years, it fell into decline during the $18^{\text {th }}$ and $19^{\text {th }}$ centuries but is poised to rise again.

Those who seek strategic insights regarding the future will find the final section to be especially significant. The underlying theme is that as China grows in power and significance, the time might come when it will attempt to assert itself as the world's dominant superpower. There has been much talk about China eventually emerging as the world's largest economy. Since China has more people than any other country, this possibility does not appear to be surprising or farfetched. Section 3 addresses these issues regarding possible tensions, responses, and risks that may arise if and when such competition takes place.

Although a useful analysis of Chinese thinking in the $21^{\text {st }}$ century, the book's message is sometimes presented in confusing ways because the translators who rendered the text into English tend to depict the thinking of the Chinese thinkers being discussed as the opinions of the authors, I contacted lead author Tian Guang regarding these perceptions, and he agreed that the goal of the book is to provide an unbiased view of Chinese thinking and that, unfortunately, the translators sometimes attributed concepts to the authors instead of adequately crediting the Chinese intellectuals being discussed. Aside from occasional confusions of this sort, the authors provide a useful commentary regarding contemporary Chinese thinking and strategies along with a discussion of their implications to politics and economics. 